\title{
Carbon Deposition from $\mathrm{CH}_{4}$ and $\mathrm{CO}$ on $\mathrm{Ni} / \mathrm{SiO}_{2}$ : Effects on the Nickel Surface Structure
}

\author{
E. G. M. Kunpers, ${ }^{* 1}$ A. J. H. M. Kock $\dagger$ G. J. Wermer $\dagger$ and J. W. Geus $\dagger$ \\ *VEG-Gasinstituut n.v., Wilmersdorf 50, P.O. Box 137, 7300 AC Apeldoorn, and †Department of Inorganic \\ Chemistry, State University of Utrecht, Croesestraat 77A, 3522 AD Utrecht, The Netherlands
}

Received January 6, 1983; revised August 24, 1983

\begin{abstract}
The activity of supported Ni catalysts for the decomposition of methane was found to be raised by subjecting the catalyst to an increasing number of carburization-decarburization cycles. Carburization was effected either by the decomposition of methane $\left(\mathrm{CH}_{4} \rightarrow \mathrm{C}(\mathrm{ads})+2 \mathrm{H}_{2}\right)$ or by the disproportionation of carbon monoxide $\left(2 \mathrm{CO} \rightarrow \mathrm{C}(\mathrm{ads})+\mathrm{CO}_{2}\right)$. Decarburization always was carried out by hydrogen $\left(\mathrm{C}+2 \mathrm{H}_{2} \rightarrow \mathrm{CH}_{4}\right)$. It was observed that the rise in activity for the decomposition of methane was related to an increased capacity of the catalyst for the chemisorption of hydrogen at $30^{\circ} \mathrm{C}$. From the results it was concluded that the surface of the nickel particles is reconstructed in the presence of carbon atoms. After reduction in $\mathrm{H}_{2}$ at $450^{\circ} \mathrm{C}$ a very small amount of strongly bound carbon remains in the surface, thus inhibiting the relaxation of the surface to its original state.
\end{abstract}

\section{INTRODUCTION}

In a previous paper $(l)$ we reported on the deposition of carbon on a $\mathrm{Ni} / \mathrm{SiO}_{2}$ catalyst by the decomposition of methane, as well as on the reactivity of the deposited carbon toward hydrogen. In subsequent experiments with a larger number of nickel catalysts it was established that the activity for the decomposition of $\mathrm{CH}_{4}$ gradually increased as a function of the number of "carburization-decarburization" cycles to which the catalyst had been subjected. Because the catalytic activity of a catalyst is determined both by the active surface area per unit weight and by the specific activity per unit surface area, we wondered if the surface of our catalysts changed during the exposure to $\mathrm{CH}_{4}$ and/or the subsequent carbon removal. We therefore determined the specific nickel surface area of one of the catalysts before and after the catalyst had been submitted to a known number of carburization-decarburization cycles. To that end hydrogen chemisorption experiments were performed at $30^{\circ} \mathrm{C}$. Because the na-

\footnotetext{
${ }^{1}$ To whom correspondence should be addressed.
}

ture of the deposited carbon was supposed to be an important variable, carbon was deposited not only by the decomposition of methane but also by the disproportionation of carbon monoxide.

The decomposition of methane was always effected in a flow system by pulsing small doses of $\mathrm{CH}_{4}$ into a nitrogen flow passing through the reactor kept at $275^{\circ} \mathrm{C}$. The disproportionation of carbon monoxide was carried out in a Pyrex high-vacuum system by admitting small doses of $\mathrm{CO}$ to the evacuated catalyst at $275^{\circ} \mathrm{C}$. Carbon deposited either by $\mathrm{CH}_{4}$ decomposition or by $\mathrm{CO}$ disproportionation was removed from the surface in a hydrogen flow at temperatures up to $450^{\circ} \mathrm{C}$. After carbon removal the catalyst was evacuated at $425^{\circ} \mathrm{C}$ and the extent of hydrogen chemisorption was measured. The value then found was compared with the hydrogen volume chemisorbed on a sample that had not been exposed to $\mathrm{CH}_{4}$ or CO previously.

\section{EXPERIMENTAL}

In the present investigation four different nickel catalysts have been used. Two nickel-on-silica catalysts, $\mathrm{U}_{42}$ and $\mathrm{U}_{46}$, were 
prepared by the method of homogeneous deposition-precipitation by means of urea decomposition at $90^{\circ} \mathrm{C}$, as described by Hermans and Geus (2) and van Dillen et al. (3). The silica used was Aerosil (Degussa, $380 \mathrm{~m}^{2} \mathrm{~g}^{-1}$ ). The precipitate of catalyst $\mathrm{U}_{42}$ contained $50 \mathrm{wt} \% \mathrm{Ni}$, whereas the weight content of $\mathrm{Ni}$ in catalyst $\mathrm{U}_{46}$ was only $11 \%$. Two other catalysts, $\mathrm{G}_{33}$ and $\mathrm{G}_{65}$, were obtained from Girdler. According to the specifications the Ni content of catalyst $\mathrm{G}_{33}$ reduced at $500^{\circ} \mathrm{C}$ was $30 \mathrm{wt} \%$, while that of catalyst $\mathrm{G}_{65}$ was $25 \mathrm{wt} \%$. The support of catalyst $\mathrm{G}_{33}$ contained $\mathrm{Al}_{2} \mathrm{Si}_{2} \mathrm{O}_{5}(\mathrm{OH})_{4}$, $\mathrm{CaCO}_{3}$ and $\mathrm{SiO}_{2}$; catalyst $\mathrm{G}_{65}$ had an alumina support to which "alkali" ( $8 \mathrm{wt} \%)$ and graphitic carbon (4 wt\%) had been added. All catalysts were dehydrated in $\mathrm{N}_{2}$ at $450{ }^{\circ} \mathrm{C}$, subsequently reduced in $10 \% \mathrm{H}_{2}$ / $90 \% \mathrm{~N}_{2}$ at the same temperature (unless indicated otherwise) for at least $80 \mathrm{~h}$, and finally degassed in a $\mathrm{N}_{2}$ flow at $450^{\circ} \mathrm{C}$ for $2 \mathrm{~h}$.

The equipment used in the experiments on the decomposition of methane was the same as described before (1). Nitrogen was deoxygenated by BASF catalyst R-3-11 (BTS catalyst), and dehydrated by Linde molecular sieve, Type 4A; hydrogen was deoxygenated by a Baker "deoxo"'-catalyst (Pd/alumina). A mixture of $10.2 \% \mathrm{CH}_{4}$ and 89.8\% $\mathrm{N}_{2}$ (impurities less than $70 \mathrm{ppm}$ ) was supplied by Matheson.

The measurements were performed with small catalyst beds (length about $1.5 \mathrm{~cm}$ and diameter $2 \mathrm{~cm}$ ); the size of the catalyst pellets varied between 1.5 and $2.5 \mathrm{~mm}$. The procedure during a typical carburizationdecarburization experiment was as follows. A dose of $0.15 \mathrm{ml}$ STP of methane was pulsed into nitrogen flowing through the reactor kept at the desired temperature $T_{1}\left(T_{1}\right.$ $\leq 350^{\circ} \mathrm{C}$ ). The $\mathrm{CH}_{4}$ conversion was determined gas chromatographically. The carbonaceous deposit was removed with $\mathrm{H}_{2}$ pulses, initially also at $T_{1}$ and subsequently at temperatures increasing from $T_{1}$ to $450^{\circ} \mathrm{C}$. Finally the catalyst sample was rereduced at $450^{\circ} \mathrm{C}$ in a flow of $10 \% \mathrm{H}_{2}$ and
$90 \% \mathrm{~N}_{2}$ for $16 \mathrm{~h}$. Prior to the next carburization-decarburization experiment at $T_{2}$ all hydrogen was removed from the catalyst surface by passing a flow of $\mathrm{N}_{2}$ through the reactor for $2 \mathrm{~h}$ at $450^{\circ} \mathrm{C}$.

Carbon deposition by means of the Boudouard reaction, $2 \mathrm{CO} \rightarrow \mathrm{C}+\mathrm{CO}_{2}$, was effected at $275^{\circ} \mathrm{C}$ on catalyst $\mathrm{U}_{42}$ only in a conventional Pyrex high-vacuum apparatus (background pressure $10^{-5}-10^{-6}$ Torr; 1 Torr $=133.3 \mathrm{Nm}^{-2}$ ) as described before (4). The carbon deposited from $\mathrm{CO}$ was removed from the nickel surface in a flow of $10 \% \mathrm{H}_{2}$ and $90 \%$ Ar during a gradual temperature rise from 22 to $450^{\circ} \mathrm{C}$.

The hydrogen chemisorption experiments were carried out at $30^{\circ} \mathrm{C}$ in the same high-vacuum apparatus as used for the Boudouard reaction; these experiments also were performed with catalyst $\mathrm{U}_{42}$ only. After reduction of the fresh catalyst, or after carbon deposition (either from $\mathrm{CH}_{4}$ or $\mathrm{CO}$ ) and subsequent removal (as indicated above), the catalyst was evacuated for at least $5 \mathrm{~h}$. The temperature maintained during evacuation was about $25^{\circ} \mathrm{C}$ below the reduction temperature to prevent desorption of water from the support and subsequent reoxidation of the nickel metal. Hydrogen used in the adsorption experiments was purified by diffusion through palladium.

The particle size distribution of catalyst $\mathrm{U}_{42}$ was obtained by means of a vibrating sample magnetometer (fields up to $14 \mathrm{kOe}$; $1 \mathrm{Oe}=79.58 \mathrm{~A} \mathrm{~m}^{-1}$ ), which also has been described earlier (4).

Transmission electron micrographs were made by means of a JEOL $200 \mathrm{C}$ electron microscope. Reduced samples were suspended in methylmethacrylate, which was polymerized at $60^{\circ} \mathrm{C}$. Ultrathin sections of these samples, suited for the electron microscope, were cut with a Reichert ultramicrotome.

\section{RESULTS AND DISCUSSION}

The decomposition of methane was investigated in pulse-flow experiments with 
four different catalysts, $\mathrm{U}_{42}, \mathrm{U}_{46}, \mathrm{G}_{33}$, and $\mathrm{G}_{65}$. As described in the experimental section a dose of $0.15 \mathrm{ml} \mathrm{STP} \mathrm{of} \mathrm{methane} \mathrm{was}$ pulsed into a nitrogen flow passing through the reactor and the conversion of $\mathrm{CH}_{4}$ was measured. Subsequently the carbonaceous deposit was removed by hydrogen pulses at increasing temperatures and finally in a continuous flow of hydrogen at $450^{\circ} \mathrm{C}$. It was observed that the $\mathrm{CH}_{4}$ conversion at a fixed temperature gradually changed as a function of the number of carburization-decarburization cycles to which the catalyst had been subjected.

Some representative results have been collected in Table 1. It can be seen that the $\mathrm{CH}_{4}$ conversion increased appreciably with the number of cycles. It was established that with the above-mentioned procedure of carbon removal within experimental error all deposited carbon reacted with $\mathrm{H}_{2}$. Methane appeared to be the only reaction product.

To investigate the effect of carbon deposition and subsequent removal on the extent of hydrogen chemisorption, catalyst $\mathrm{U}_{42}$ (see Table 1) was passivated in a flow of 1 vol\% of $\mathrm{O}_{2}$ in $\mathrm{N}_{2}$ and afterward transferred to the sample cell of the static adsorption apparatus. In Fig. 1 the hydrogen isotherm measured at $30^{\circ} \mathrm{C}$ with the rereduced and evacuated sample is shown. In Fig. 1 also the $\mathrm{H}_{2}$ isotherm obtained with a freshly reduced sample of catalyst $\mathrm{U}_{42}$ that had not been exposed to $\mathrm{CH}_{4}$ previously is represented. It is evident that the amount of hydrogen chemisorbed, $V\left(\mathrm{H}_{2}\right)$, was strongly enlarged by subjecting the catalyst to more than 40 carburization-decarburization cycles. At a hydrogen pressure of 300 Torr $V\left(\mathrm{H}_{2}\right)$ had increased by about $50 \%$, while the $\mathrm{CH}_{4}$ conversion had increased from 78 to $93 \%$ (Table 1 ).

Reaction with methane and subsequent removal of the carbonaceous deposit with $\mathrm{H}_{2}$ has also been carried out with the catalyst sample already in the measuring cell of the adsorption apparatus. In this way an intermediate passivation of the sample was
TABLE 1

The Conversion of a $\mathrm{CH}_{4}$ Pulse at $200^{\circ} \mathrm{C}$ on Various Catalysts as a Function of the Number of

Carburization-Decarburization Cycles Performed

\begin{tabular}{ccccc} 
Catalyst & $\begin{array}{c}\text { Reduction } \\
\text { temperature } \\
\left({ }^{\circ} \mathrm{C}\right)\end{array}$ & $\begin{array}{c}\text { Conversion during } \\
\text { first carhurization } \\
(\%)\end{array}$ & $\begin{array}{c}\text { Conversion during } \\
n \text {th carburization } \\
(\%)\end{array}$ \\
\hline $\mathrm{U}_{42}$ & 450 & 78 & 740 & 93 \\
$\mathrm{U}_{46}$ & 450 & 62 & 2 & 79 \\
$\mathrm{G}_{33}$ & 500 & 68 & 5 & 79 \\
$\mathrm{G}_{65}$ & 625 & 44 & 6 & 63
\end{tabular}

prevented. After the sample had been exposed to 270 pulses of $0.15 \mathrm{ml} \mathrm{STP} \mathrm{of} \mathrm{CH}_{4}$ at $275^{\circ} \mathrm{C}$ (four pulses per hour), the deposited carbon was removed in the usual way. As a result of this treatment the extent of hydrogen chemisorption on the sample rose by $13 \%$.

In the adsorption apparatus a sample of catalyst $U_{42}$ was carburized three times by carbon from carbon monoxide according to $2 \mathrm{CO} \rightarrow \mathrm{C}+\mathrm{CO}_{2}$. After each carburization the carbonaceous deposit was removed from the surface by reaction with $\mathrm{H}_{2}$. Prior to and after the three carburization-decarburization cycles hydrogen was adsorbed on the sample at $30^{\circ} \mathrm{C}$. The results are represented in Fig. 2. Again the extent of hydrogen chemisorption increased due to carbon deposition and subsequent removal, now by about $15 \%$.

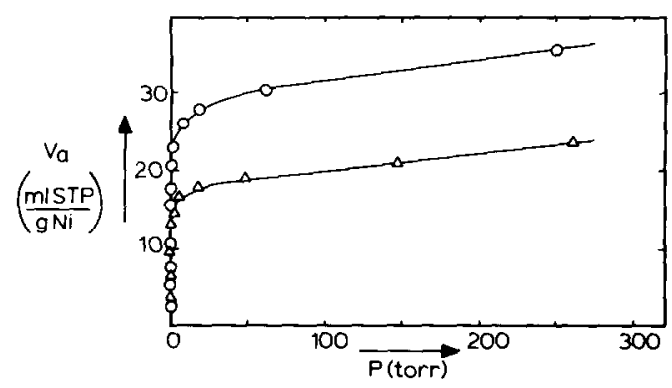

FIG. 1. Isotherms for hydrogen chemisorption at $30^{\circ} \mathrm{C}$ on a sample of catalyst $\mathrm{U}_{42}$ (carburization was effected by means of $\mathrm{CH}_{4}$ decomposition). ( $\triangle$ ) Prior to carburization-decarburization experiments, $(O)$ after carburization-decarburization experiments. 


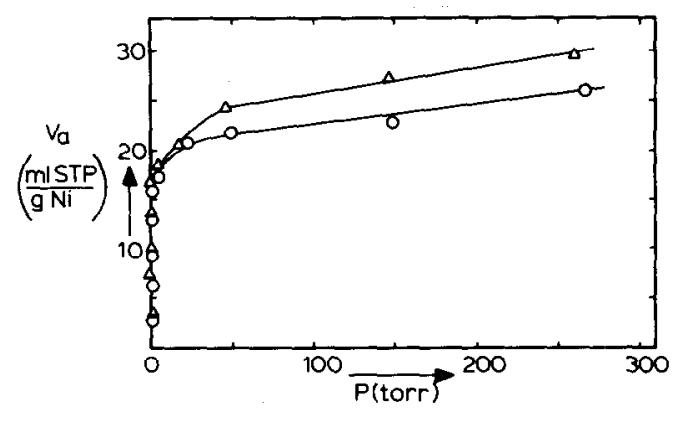

FIG. 2. Isotherms for hydrogen chemisorption at $30^{\circ} \mathrm{C}$ on a sample of catalyst $\mathrm{U}_{42}$ (carburization was effected by means of $\mathrm{CO}$ disproportionation). (O) Prior to carburization-decarburization experiments, $(\Delta)$ after carburization-decarburization experiments.

The most obvious inference is to ascribe the increased hydrogen chemisorption to a higher degree of reduction, $x$, caused by the successive treatments with $\mathrm{CH}_{4}$ or $\mathrm{CO}$ and $\mathrm{H}_{2}$. We therefore determined the degree of reduction of the sample before and after the experiments of Fig. 2 by measuring the saturation magnetization at $77 \mathrm{~K}$ and at a magnetic field strength of $14 \mathrm{kOe}$. The degree of reduction appeared to have increased only from 71 to $75 \%$ in the course of the experiments; this increase in $x$ is too small to lead to a rise in the nickel surface area of about $15 \%$. We also measured the particle size distributions of the sample of Fig. 2. Figure 3 shows the results. In this figure the increment of the nickel volume $V$ in intervals $d(\log r)$ is represented as a function of the radius $(r)$ of the nickel particles. It can be seen that the particle size distribution hardly changed during the experiments. More quantitatively the specific nickel surface area, as calculated from the particle size distribution, decreased by about $15 \%$, probably because of a little sintering during the subsequent reductions (the fresh sample had been reduced at $450^{\circ} \mathrm{C}$ for $80 \mathrm{~h}$, whereas eventually the sample had been kept at $450^{\circ} \mathrm{C}$ for $925 \mathrm{~h}$ ). Hence the increase in $V\left(\mathrm{H}_{2}\right)$ by about $15 \%$ has to be compared with the decrease in $S_{\mathrm{Ni}}$ by about $15 \%$ calculated from the magnetically obtained particle size distributions. Apparently, the process of carburization and subsequent decarburization raises the extent of hydrogen chemisorption per unit surface area of nickel.

That also the catalytic activity per unit surface area of nickel was raised by (de-) carburization is demonstrated unambiguously by the following experiment. A sample of catalyst $\mathrm{G}_{65}$ was reduced at $450^{\circ} \mathrm{C}$ and subsequently exposed to a pulse of methane $(0.15 \mathrm{ml} \mathrm{STP})$ at $300^{\circ} \mathrm{C}$; the conversion measured was $83 \%$. Subsequently the sample was reduced at $625^{\circ} \mathrm{C}$. The transmission electron micrographs of Fig. 4 show that during this high-temperature treatment appreciable sintering occurred. As was to be expected, the conversion found $(51 \%)$ was considerably smaller than before. Obviously the appreciable drop in the nickel surface area evident from Fig. 4 leads to the decreased conversion. After the sample had been (de-)carburized repeatedly, a new measurement of the $\mathrm{CH}_{4}$ conversion at $300^{\circ} \mathrm{C}$ yielded a value of $90 \%$. This high conversion was preserved even after another high-temperature reduction at $625^{\circ} \mathrm{C}$.

From the above experiments we conclude that the deposition of carbon on the nickel surface, either from $\mathrm{CH}_{4}$ or $\mathrm{CO}$, leads to a change in the surface structure of the Ni particles. It has been found that within experimental error all carbon was removed from the surface prior to $\mathrm{H}_{2}$ chemi-

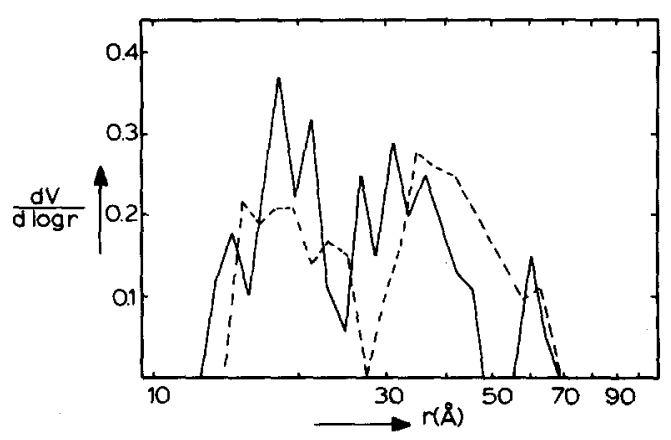

FIG. 3. Particle size distribution of catalyst $\mathrm{U}_{42}$. (-) Prior to carburization-decarburization experiments, (--) after carburization-decarburization experiments. 

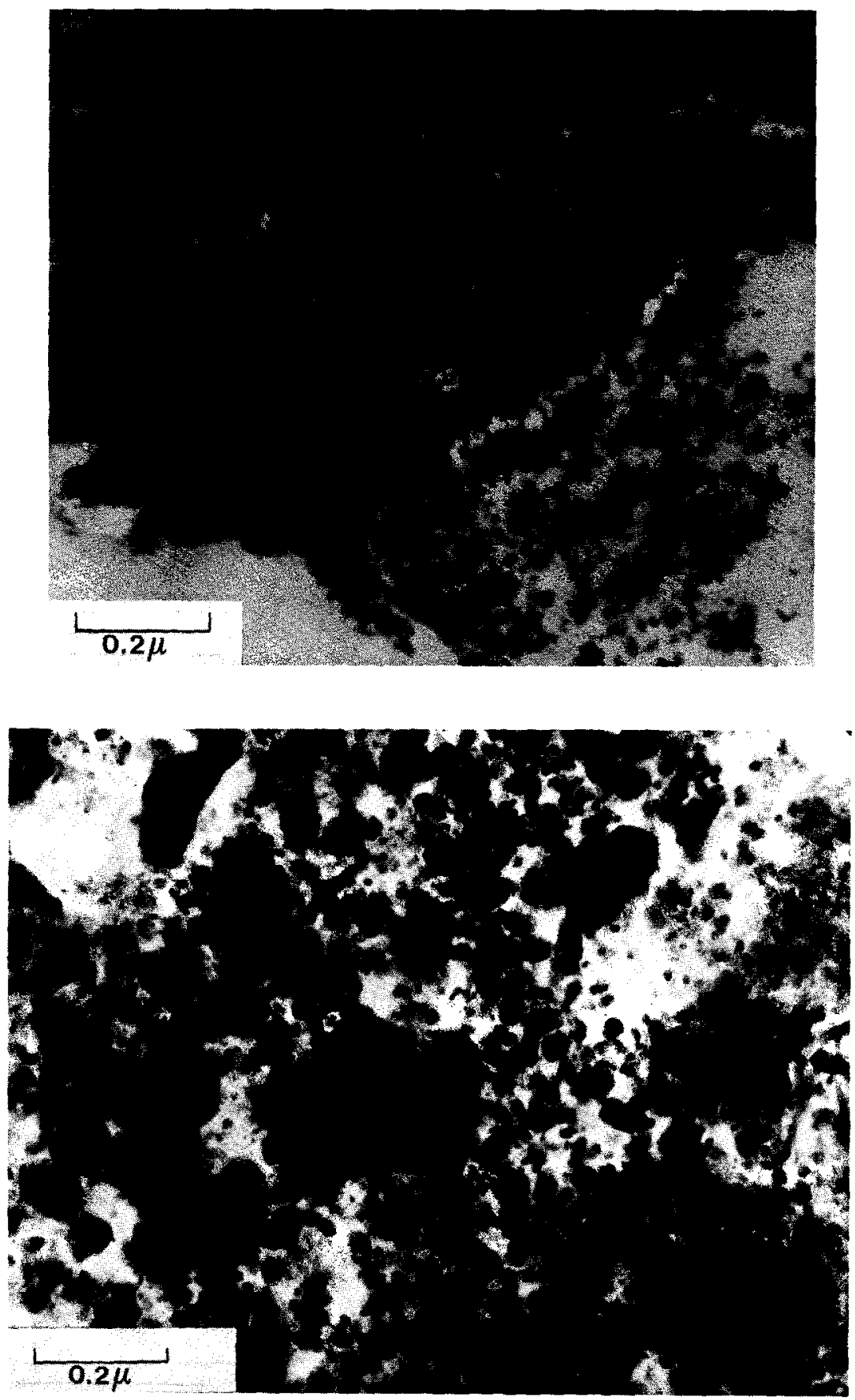

FIG. 4. Transmission electron micrographs of catalyst $\mathrm{G}_{65}$. Above: after reduction at $450^{\circ} \mathrm{C}$. Below: after reduction at $625^{\circ} \mathrm{C}$. 
sorption. Nickel atoms have been shown to be highly mobile over Ni surfaces (5). Nevertheless, even prolonged treatment of catalyst $\mathrm{G}_{65}$ in hydrogen at $625^{\circ} \mathrm{C}$ did not restore the original, lower activity for the decomposition of methane. We therefore have to accept that a very small number of strongly bound carbon atoms remains in the surface after treatment with $\mathrm{H}_{2}$ at 450 or even $625^{\circ} \mathrm{C}$, thus inhibiting the relaxation of the surface to its original state. Reportedly (6) carbon atoms strongly reduce the mobility of tungsten atoms on tungsten surfaces, and apparently on nickel they operate analogously. On the carbon-containing, reconstructed surface more hydrogen can be chemisorbed and the activity for the decomposition of methane is higher. A rearrangement of iron surfaces brought about by sorption of carbon atoms (and a corresponding increase in the sorption capacity of the catalyst) has also been found by Kieffer (7). This author also observed that the surface remained reconstructed during temperature-programmed reduction with $\mathrm{H}_{2}$. Frennet and Liénard (8) have reported an increase in the surface area of their nickel films in a study of the decomposition of methane. The authors conclude that a reconstruction of the surface proceeds proportionally to the number of sorbed carbon atoms. A similar rearrangement of the surface nickel atoms may also explain the results reported by Araki and Ponec (9), who studied the methanation reaction on $\mathrm{Ni}$ films. Starting with a mixture of ${ }^{12} \mathrm{CO}$ and $\mathrm{H}_{2}$ they observed that the initial rate of ${ }^{12} \mathrm{CH}_{4}$ formation on a film with preadsorbed ${ }^{13} \mathrm{C}$ was larger than on the bare film. Our results suggest that the preadsorbed ${ }^{13} \mathrm{C}$ brought about a change in the surface structure of the film leading to an enhanced methanation activity.

Recently Coenen et al. (10) and van Meerten et al. (11) have mentioned a rather peculiar behavior of $\mathrm{Ni} / \mathrm{SiO}_{2}$ catalysts during the methanation reaction. Although they observed by means of magnetic measurements that the mean diameter of their nickel particles increased substantially during the reaction at $208^{\circ} \mathrm{C}$, the activity of their catalysts hardly changed. Stated otherwise, the activity per unit surface area of nickel increased, while the activity per gram of nickel did not change. According to the authors the growing particle size is to be ascribed to sintering by transport of nickel from small to large particles via nickel carbonyl, $\mathrm{Ni}(\mathrm{CO})_{4}$. When the growth of the $\mathrm{Ni}$ particles with the consequent decrease in $S_{\mathrm{Ni}}$ and in catalytic activity balances the increase in activity brought about by the reconstruction of the surface during the methanation reaction, the overall activity can be expected to remain almost constant.

Coenen et al. (10) and van Meerten et al. (11) also measured the extent of $\mathrm{H}_{2}$ chemisorption on their samples after $11 \mathrm{~h}$ of methanation. In agreement with their magnetic results a decrease in $S_{\mathrm{Ni}}$ was found. Our results, however, show that on the reconstructed surface more hydrogen can be chemisorbed per unit surface area of $\mathrm{Ni}$ (Figs. 1 and 2). The difference between their results and ours must be due to a different pretreatment of the catalyst prior to hydrogen chemisorption. The carbon was removed from our samples by heating to $450^{\circ} \mathrm{C}$ in $\mathrm{H}_{2}$, whereas the carbon deposits of van Meerten et al. were removed by exposure to air at $450^{\circ} \mathrm{C}$, followed by a re-reduction in $\mathrm{H}_{2}$. As dealt with above, the treatment in $\mathrm{H}_{2}$ alone does not eliminate all surface carbon. As long as the surface contains carbon atoms, the relaxation to its bare state is inhibited. When, however, carbon is burned off in air, no carbon is left in the surface, and the original surface structure is restored.

\section{REFERENCES}

1. Kuijpers, E. G. M., Jansen, J. W., van Dillen, A. J., and Geus, J. W., J. Catal. 72, 75 (1981).

2. Hermans, L. A. M., and Geus, J. W., in "Preparation of Catalysts, II" (B. Delmon, P. Grange. P. Jacobs, and G. Poncelet, Eds.), p. 113. Elsevier, Amsterdam, 1979.

3. van Dillen, A. J., Geus, J. W., Hermans, L. A. M., and van der Meijden, J., in "Proceedings, 
Sixth International Congress on Catalysis (London, 1976)" (G. C. Bond, P. B. Wells, and F. C. Tompkins, Eds.), Vol. 2, p. 677. The Chemical Society, London, 1977.

4. Kuijpers, E. G. M., Breedijk, A. K., van der Wal, W. J. J., and Geus, J. W., J. Catal. 72, 210 (1981).

5. Melmed, A. J., J. Appl. Phys. 38, 1885 (1967).

6. Bettler, P. C., Bennum, D. H., and Case, C. M., Surf. Sci. 44, 360 (1974).

7. Kieffer, E. P., Ph.D. thesis, Eindhoven, 1981.
8. Frennet, A., and Liénard, G., J. Chim. Phys. Physicochim. Biol. 68, 1526 (1971).

9. Araki, M., and Ponec, V., J. Catal. 44, 439 (1976).

10. Coenen, J. W. E., Schats, W. M. T. M., and van Meerten, R. Z. C., Bull. Soc. Chim. Belg. 88, 435 (1979).

11. van Meerten, R. Z. C., Habets, H. M. J., Beaumont, A. H. G. M., and Coenen, J. W. E., "Proceedings, 7th International Congress on Catalysis (Tokyo, 1980),"' p. 1440. Elsevier, Amsterdam, 1981. 